\title{
Flatus and toilet air may be routes for faecal-oral infection
}

\author{
Ryoichi Matsuda* \\ Department of Science Education, Graduate School of Science, Tokyo University of Science, 1-3 Kagurazaka, Shinjuku-ku, Tokyo 162-8601, Japan
}

\begin{abstract}
Flatus that passes through an individual's clothing into the atmosphere contains a substantial number of enteric bacteria. Airborne bacteria were also found in toilet air after defecation. From the literature, SARS-CoV-2 RNA has been found in patients' stool and sewage. Although the present study did not attempt to isolate any SARS-CoV-2, the results suggest that flatus and toilet air are potential routes for fecal and oral transmission of SARS-CoV-2. The new variants are shown to spread more easily between humans, and this hidden route should be aware of virus transmission.
\end{abstract}

\section{Introduction}

The pandemic caused by a novel coronavirus, severe acute respiratory syndrome coronavirus 2 (SARS-COV-2), has become a significant threat. The Worldometer showed that the total number of coronavirus disease, COVID-19 cases were 67,129,356 and 1,541,598 deaths as ofDecember 4,2020 . These numbers continue to increase significantly. Accumulating evidence has shown the faecal-oral transmission of SARS-COV-2 through the gastrointestinal system [1-4]. An elevated level of airborne SARS-COV-2 has been found in patients' toilet areas [5-7]. Viral contamination by aerosols generated by toilet use has been reported previously [8]. I became interested in whether flatus and toilet air after defecation could also cause viral infection through the faecal-oral route. In this study, I used enteric bacteria as a possible model representing SARS-COV-2 exist in the digestive duct and showed a significant number of bacteria exist in flatus and toilet air. Although the present study has no direct evidence on SARS-COV-2, the result suggests the flatus emitted from COVID patients and in toilet air after their use are the possible routes of the virus infection.

\section{Materials and methods}

Bacterial agar plates were prepared with DAIGO, Fuji Film-Wako, Co., Tokyo, Japan. After incubation at $37^{\circ} \mathrm{C}$ for $3-5$ days, the total number of bacterial colonies grown on the agar plates was counted. The outer surface of my anal area was cleaned thoroughly with $75 \%$ alcohol to prevent contamination from bacteria on the skin. Bacteria detected in flatus emitted on 90-mm bacterial agar plates: a) without flatus as a control, b) once directly, c) once through one layer of autoclaved $93 \%$ cotton briefs, d) once through one layer of autoclaved briefs and one layer of autoclaved $100 \%$ wool trousers.

Bacteria detected in the atmosphere of a private toilet room in: e) a 90-mm bacterial agar plate placed on an alcohol-cleaned toilet seat for 2 min immediately after defecation and flushing, f) placed upside-down on the toilet seat for 2 min after defecation, g) a $90-\mathrm{mm}$ bacterial agar plate inserted in the space between the legs and toilet seat during defecation without flushing. The collecting method used for ( $\mathrm{g}$ ) is shown in $\mathrm{h}$ ). All plates were incubated for three days. Bacterial leakage through a pant-type paper adult diaper was also studied. An agar plate placed $3 \mathrm{~cm}$ beneath the adult diapers (thin unisex type, white M-L, "Kao Relief," Kao Co., Tokyo, Japan), and flatus emitted once through the diaper. Each observation was repeated three times. The subject person, I, was completely naked, wiped with $75 \%$ alcohol, and did not use a bidet-toilet, toilet paper, and flushing to avoid further contamination.

\section{Results and discussion}

A significant number of bacterial colonies observed from flatus emitted directly onto the agar plates and from flatus that passed through one layer of cotton briefs. Bacteria also were detected from the atmosphere that passed through a pair of cotton briefs and one layer of wool trousers (Figure 1b, Figure 1c, and Figure 1d). The size of viral aerosols is similar to or smaller than that of bacterial aerosols, and it will easily passthrough briefs and trousers.

The atmosphere of the toilet room contained bacteria (Figure 1e). The air derived from the space between legs during defecation also included many bacteria (Figure 1g). When flatus emitted through a paper adult diaper, no bacteria grew on the agar plates (Table 1 adult diaper). Suggesting that the paper diaper absorbed the bacteria in the flatus, preventing the leakage of bacteria to the air. Therefore, wearing adult diapers may also help avoid fecal-oral infection of norovirus, rotavirus, Shigella, or other pathogens. Many bacterial colonies also grew on the Plate placed on the toilet seat or exposed to the toilet bowl air after defecation, suggesting that the private toilet room's air contained a significant number of bacteria after use. A considerable number of bacteria are also detected in the air released from the space between the legs and the toilet seat. These bacterial aerosols are inhaled by the person currently using the toilet room or the next person in a busy toilet room.

Although I did not intend to detect any SARS-COV-2, it is reasonable to assume that viral transmission may occur through flatus or toilet air

*Correspondence to: Ryoichi Matsuda, Department of Science Education, Graduate School of Science, Tokyo University of Science, 1-3 Kagurazaka, Shinjuku-ku, Tokyo 162-8601, Japan, Tel: +81-3-5228-8279, Fax: +81-3-52288279; E-mail: cmatsuda@rs.tus.ac.jp

Key words: SARS-CoV-2, faecal-oral infection, enteric bacteria, toilet air

Received: December 07, 2020; Accepted: December 24, 2020; Published: December 28, 2020 

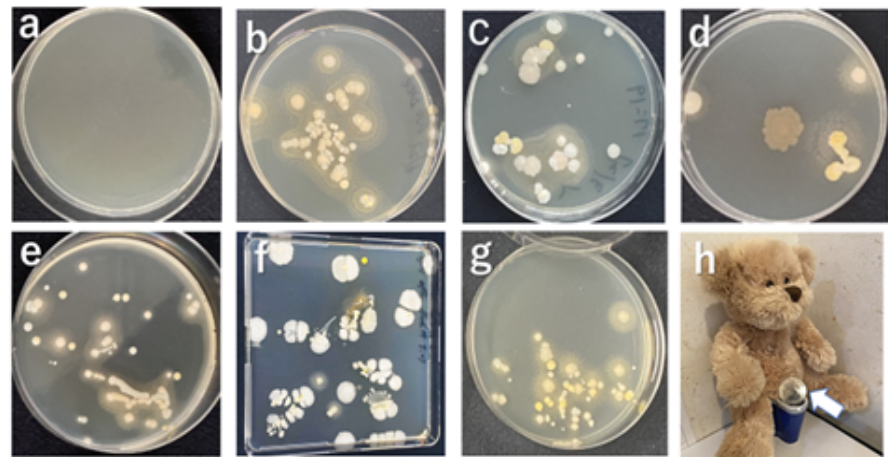

Figure 1. Photographs of bacterial colonies grown on agar plates. a) Control, no flatus exposure and cultured for three days. b) Exposure to flatus directly, once, and cultured for three days. c) Exposure to flatus once through one layer of cotton briefs and cultured for three days. d) Exposure to flatus once through briefs and trousers and cultured for three days. e) Exposure to the atmosphere in a private toilet room for $2 \mathrm{~min}$ after use and cultured for three days. f) Exposure of a $24 \mathrm{~cm}$-large agar plate to the air in the toilet bowl after defecation for $2 \mathrm{~min}$ and cultured for 7 days. g) Exposure to the air came from the space between legs during defecation and cultured for three days. h) Method of " $\mathrm{g}$ " for collecting bacteria released from the space between legs during defecation.

Table 1. Direct- Flatus is emitted once directly onto the Plate. Cotton 1 (C1)- Flatus emitted once through one pair of cotton briefs. $\mathrm{C} 1+$ Trousers- Flatus emitted once through one pair of briefs and one pair of trousers. Adult Diaper- Flatus is emitted once through one pair of disposable adult paper diapers. Before- Plate was placed on the toilet seat and exposed to the air for $2 \mathrm{~min}$ in a private toilet room before use. After- Plate was placed on the toilet seat and exposed to the air for $2 \mathrm{~min}$ immediately after defecation in a private toilet room.

\begin{tabular}{|l|c|c|c|c|c|c|}
\hline & Direct & $\begin{array}{c}\text { Cotton 1 } \\
\text { (C1) }\end{array}$ & C1+Trousers & $\begin{array}{c}\text { Adult } \\
\text { Diaper }\end{array}$ & Before & After \\
\hline AVE & 90.3 & 29.3 & 3.3 & 0 & 0 & 42.7 \\
\hline SD & 29.3 & 2.3 & 4.2 & 0 & 0 & 13.6 \\
\hline $\mathbf{n}$ & 3 & 3 & 7 & 3 & 3 & 3 \\
\hline
\end{tabular}

after a SARS-COV-2-infected person has used it. Since flatus can be considered similar to cough or sneeze from the anus, it is one way to wear leakproof underwear is analogous to using a facial mask. The new variants may spread more easily between humans than the original one [9]; this hidden route may be aware of virus transmission. Using a wellventilated toilet room, wearing a mask, cleaning the toilet seat before/ after use, covering the space between legs on the toilet seat with layers of toilet paper during defecation, and closing the toilet bowl lid before flushing will become common behaviours in our "new-normal lives."

In conclusion, we should pay more attention to flatus and toilet air as possible routes of SARS-COV-2 infection.

\section{Funding}

This study was supported in part by an Intramural Research Grant (29-4) for Neurological and Psychiatric Disorders from the National Center of Neurology and Psychiatry (NCNP), Japan.

\section{Acknowledgment}

I want to thank Drs. Okamoto T, Sato JD, Bandman E, and Mabuchi I for their critical review of the manuscript.

\section{References}

1. Cheung KS, Hung IFN, Chan PP, Lung KC, Tso E, et al. (2020) Gastrointestinal manifestations of SARS-CoV-2 infection and virus load in fecal samples from a Hong Kong cohort: systemic review and meta-analysis. Gastroenterology 159: 81-95. [Crossref]

2. Mukhra R, Krishan K, Kanchan T (2020) Possible models of transmission of novel coronavirus SARS-CoV-2: a review. Acta Biomed 91: e2020036. [Crossref]

3. Xiao F, Tang M, Zheng X, Liu Y, Li X, et al. (2020) Evidence for gastrointestinal infection of SARS-CoV-2. Gastroenterology 158: 1831-1833. [Crossref]

4. Zhang W, Du RH, Li B, Zheng XS, Yang XL, et al. (2020) Molecular and serological investigation of 2019-nCoV infected patients: implication of multiple shedding routes. Emerging Microbes and Infect 9: 386-389. [Crossref]

5. Verani M, Bigazzi R, Carducci A (2014). Viral contamination of aerosol and surface through toilet use in health care and other settings. Amer J of Infect Control 42: 758762. [Crossref]

6. Amirian ES (2020) Potential fecal transmission of SARS-CoV-2: Current evidence and implications for public health. Int J Infect Disorders 95: 363-370. [Crossref]

7. Patel KP, Vunnam SR, Patel PA, Krill KL, Korbitz PM, et al. (2020) Transmission of SARS-Cov-2: an update of current literature. Eur J Clinical Microbiol Infect Diseases 7: 1-7. [Crossref]

8. Baker J, Jones MV (2005) The potential spread of infection is caused by aerosol contamination of surfaces after flushing a domestic toilet. J Appl Microbiol 99: 339347. [Crossref]

9. Plante JA, Liu Y, Liu J, Xa H, Johnson BA, et al. (2020) Spike mutation D614G alters SARS-CoV-2 fitness. Nature 592: 116-121. [Crossref]

Copyright: (C2020 Matsuda R. This is an open-access article distributed under the terms of the Creative Commons Attribution License, which permits unrestricted use, distribution, and reproduction in any medium, provided the original author and source are credited. 